\title{
Simpson Grading System
}

National Cancer Institute

\section{Source}

National Cancer Institute. Simpson Grading System. NCI Thesaurus. Code C128616.

A scale that defines the extent of resection involved in the removal of intracranial meningiomas. 